\title{
SISTEMA DE GESTÃo PEDAGÓGICA (SGP) E AVALIAÇÃO ESCOLAR: A INFLUÊNCIA DE UMA TECNOLOGIA NO AGIR DO COORDENADOR PEDAGÓGICO
}

\author{
SISTEMA DE GÉSTION PEDAGÓGICA (SGP) Y EVALUACIÓN ESCOLAR: LA \\ INFLUENCIA DE UMA TECNOLOGÍA EM EL ACTUAR DEL COORDINADOR \\ PEDAGÓGICO
}

\section{PEDAGOGICAL MANAGEMENT SYSTEM (SGP) AND SCHOOL EVALUATION: THE INFLUENCE OF A TECHNOLOGY ON THE PEDAGOGICAL COORDINATOR'S ACTION}

\author{
Claudia Gonçalves da SILVA ${ }^{1}$ \\ Ricardo dos SANTOS ${ }^{2}$
}

\begin{abstract}
RESUMO: Este trabalho tem como objetivo abordar a influência do Sistema de Gestão Pedagógica (SGP) - ferramenta tecnológica para registro pedagógico utilizado pela Rede Municipal de Ensino da Cidade de São Paulo - nas ações dos Coordenadores Pedagógicos ante à avaliação escolar. Foi realizado um estudo bibliográfico sobre avaliação para a aprendizagem, a função do Coordenador Pedagógico frente as atividades avaliativas, os recursos tecnológicos como facilitadores das ações avaliativas escolares e as funcionalidades existentes no SGP. Além disso, uma pesquisa de campo foi feita com Coordenadores Pedagógicos de escolas do Ensino Fundamental da Rede Municipal de São Paulo. Em uma junção entre tecnologia e pedagogia, o presente trabalho colabora para a reflexão sobre a qualidade de ensino, abordando o viés da avaliação escolar, com ênfase na aprendizagem para todos os alunos.
\end{abstract}

PALAVRAS-CHAVE: Educação. Avaliação. SGP.

RESUMEN: Este trabajo tiene como objetivo abordar la influencia del Sistema de Gestión Pedagógica (SGP) - herramienta tecnológica para registro pedagógico utilizado por la Red Municipal de Enseñanza de la Ciudad de São Paulo - en las acciones de los Coordinadores Pedagógicos ante la evaluación escolar. Se realizó un estudio bibliográfico sobre evaluación para el aprendizaje, la función del Coordinador Pedagógico frente a las actividades evaluativas, los recursos tecnológicos como facilitadores de las acciones evaluativas escolares y las funcionalidades existentes en el SGP. Además, una encuesta de campo fue hecha con Coordinadores Pedagógicos de escuelas de la Enseñanza Fundamental de la Red Municipal de São Paulo. En una unión entre tecnología y pedagogía, el presente trabajo colabora para la reflexión sobre la calidad de la enseñanza, abordando el sesgo de la evaluación escolar, con énfasis en el aprendizaje para todos los alumnos.

PALABRAS CLAVE: Educación. Evaluación. SGP.

${ }^{1}$ Universidade Tecnológica Federal do Paraná - (UTFPr), Medianeira - Paraná - Brasil. Especialista em Educação: Métodos e Técnicas de Ensino. ORCID: http://orcid.org/0000-0002-7625-570X. E-mail: claugons@ hotmail.com ${ }^{2}$ Universidade Tecnológica Federal do Paraná - (UTFPr), Medianeira - Paraná - Brasil. Professor efetivo. Chefe do Departamento Acadêmico de Ciências Humanas, Letras e Artes. ORCID: http://orcid.org/0000-0003-12662880. E-mail: rsantos@utfpr.edu.br 
ABSTRACT: This work aims to address the influence of the Pedagogical Management System (SGP) - a technological tool for pedagogical registration used by the Municipal Education Network of the City of São Paulo - in the actions of the Pedagogical Coordinators in front of the school evaluation. A bibliographic study was carried out on evaluation for learning, the role of the Pedagogical Coordinator in relation to the evaluation activities, the technological resources as facilitators of the school evaluation actions and the functionalities existing in the SGP. In addition, a field research was done with Pedagogical Coordinators of elementary schools of the Municipal Network of São Paulo. In a junction between technology and pedagogy, the present work contributes to the reflection on the quality of teaching, addressing the bias of school evaluation, with emphasis on learning for all students.

KEYWORDS: Education. Evaluation. SGP.

\section{Introdução}

Esta pesquisa teve como objetivo abordar a influência do Sistema de Gestão Pedagógica (SGP), como ferramenta tecnológica, na orientação realizada pelos coordenadores pedagógicos frente às ações didáticas avaliativas em escolas de ensino fundamental do município de São Paulo, da Diretoria Regional de Educação - Santo Amaro (DRESA). Com base nos dados oferecidos por três escolas municipais da região de Santo Amaro, foi possível analisar como o SGP contribui para o trabalho do Coordenador Pedagógico em prol da qualificação das ações pedagógicas no processo avaliativo dos alunos do ensino fundamental II.

Os dados foram coletados a partir da pesquisa de campo realizada por meio de questionário aplicado em coordenadores pedagógicos que apresentaram, em encontros formativos realizados na Diretoria Regional de Educação - Santo Amaro, comprometimento na utilização do SGP no cotidiano da gestão escolar, podendo, assim, colaborar com assertividade no que se refere às funcionalidades do sistema.

O interesse por esta pesquisa aconteceu após a implementação do SGP, que se iniciou nas escolas municipais do Ensino Fundamental de São Paulo, em fevereiro de 2014, através da Portaria 1.224. As Unidades Educacionais, até então, historicamente, habituadas a fazerem seus registros pedagógicos no Diário de classe impresso, se depararam com uma ferramenta tecnológica que armazena todos os dados didáticos de maneira digital. Era, assim, o início de um grande desafio (que perdura até os dias de hoje, visto que a Portaria em questão é, relativamente, recente).

O SGP, por sua transparência e acessibilidade, repercute nas ações didáticas dos educadores e propicia a reflexão sobre a influência da tecnologia no agir pedagógico. O sistema, diferentemente dos registros impressos, não permite a inserção de dados fora do período 
bimestral vigente; vincula a atribuição de conceitos finais a, pelo menos, uma atividade avaliativa registrada; permite que os educadores acompanhem, em tempo real, a porcentagem de frequência de cada aluno; possibilita que os coordenadores pedagógicos visualizem o rendimento escolar de cada educando/turma; entre outras funções.

Assim, após a implantação do SGP, algumas ações pedagógicas precisaram ser revistas e adequadas. O que, antes, o "papel aceitava", o sistema não aceita mais. Além disso, as funcionalidades disponíveis possibilitam uma análise dos registros pedagógicos e oportunizam a reflexão da equipe gestora diante do processo de aprendizagem dos alunos. A escola se vê diante de um recurso tecnológico que exige além dos registros digitais, o compromisso com a qualificação do ensino. Esta nova dinâmica educacional no movimento de ensino e aprendizagem, proporcionada pelo SGP, é foco desta pesquisa.

\section{O que é o SGP?}

O Sistema de Gestão Pedagógica (SGP) é um sistema tecnológico que organiza, armazena e gerencia os registros pedagógicos. As informações educacionais contidas no SGP (planos de aula, frequência, atividades avaliativas, notas, conceitos finais, entre outros) são inseridas por educadores, ou seja, o sistema não faz preenchimentos pedagógicos automáticos. Após a inserção e a consolidação dos dados (realizadas bimestralmente), os pais/responsáveis podem acessar o boletim escolar (que contém as notas/conceitos bimestrais e observações realizadas pelos educadores); já os professores e gestores escolares conseguem acessar e analisar os dados pedagógicos, de sua escola, em forma de relatórios, gráficos e planilhas que sintetizam a trajetória dos alunos. Ao organizar o acompanhamento pedagógico, em forma de documentos sintéticos (e sintetizar não significa reduzir ou omitir dados, mas facilitar a análise geral do conjunto de informações), é possível diagnosticar demandas e identificar qualidades, fundamentando o direcionamento da equipe gestora para as ações pedagógicas dos educadores, favorecendo à uma educação de qualidade.

O SGP constitui-se, assim, como além de uma ferramenta para registros digitais, tornase, portanto, um instrumento tecnológico facilitador da reflexão do processo de ensino e aprendizagem, auxiliando no trabalho da equipe gestora (ressalta-se aqui, a importância da ação do coordenador pedagógico, gestor-chave para a formação docente) na tomada de decisões para o alcance dos objetivos pedagógicos da Unidade Educacional.

\section{Funcionalidades do SGP}

RPGE- Revista on line de Política e Gestão Educacional, Araraquara, v. 24, n. 1, p. 86-99, jan./abr. 2020. e-ISSN:1519-9029. 
O SGP constitui-se de variadas funcionalidades que vão desde os registros diários referentes à frequência e ao plano de aula, aos relatórios para os gestores que consolidem dados do processo educativo. Todos os registros são feitos de forma digital (por endereço eletrônico - SGP Web ${ }^{3}$ ou pelo Portal da Secretaria Municipal de Educação) através de computadores com conexão à internet ou por aplicativo instalado em tablets (SGP tablet). Os tablets relacionados como bens patrimoniais da Unidade Educacional permitem que, em caso de falta de conexão à internet, os registros sejam feitos offline e, após sincronização dos tablets, as informações são atualizadas no SGP.

Para acesso ao SGP, o servidor público municipal informa seu Registro Funcional e sua senha.

\section{Registro docente}

Ao logar no sistema, se o servidor tiver turmas atribuídas para aquele ano letivo, a página inicial apresentará sua(s) turma(s), curso, turno, tipo de docência e aulas dadas. Nesta funcionalidade, chamada Minhas Turmas, o docente visualiza suas turmas e acessa ícones de cada sala. Abaixo segue a explicação resumida de cada campo e seu funcionamento:

a) Aulas dadas:

Apresentação da visão geral das aulas previstas, cumpridas e repostas do ano letivo naquela turma, por bimestre.

b) Planejamento:

Permite visualização dos registros realizados pelos educadores referentes ao Planejamento Anual (o qual é subdividido em abas para Diagnóstico Inicial da turma e Bimestres), Plano para o aluno (em caso de planejamento específico para um educando), Documentos (com Documentos Federais, Municipais e de cada Unidade Educacional - UE).

c) Diário de Classe:

Ferramenta que exibe e permite os registros diários do professor: planos de aula, frequência, atividades avaliativas e anotações. Ao clicar no campo Plano de Aula é possível observar o planejamento da aula, seu objetivo e o(s) conteúdo(s) trabalhado(s) com a turma. No campo de Frequência há o apontamento das frequências e ausências dos educandos (sendo que o professor aponta, somente, as ausências, os campos não indicados pelo docente, são lidos pelo sistema como presença dos alunos). No campo Atividades Avaliativas, o educador registra as

${ }^{3}$ Disponível em: http://sgp.sme.prefeitura.sp.gov.br. Acesso em: 10 mar. 2020. 
avaliações dadas aos estudantes. Já no campo de Anotações, o docente faz registros que julgue como pertinentes e válidos à aula do dia. Todos estes campos ficam disponíveis para serem realizados pelo professor durante a vigência do bimestre em questão. A equipe gestora da UE não tem permissão para registrar estes campos apresentados.

d) Listão:

Subdivide-se em Listão de frequência, Listão de Avaliação e Listão de plano de aula, todos permitem visualização completa dos dados referentes às ausências e presenças, atividades avaliativas cadastradas e planos de aula do bimestre.

No Listão de frequência também é possível marcar a frequência dos alunos (assim, o registro de frequência pode ser feito no Diário de classe ou no Listão), bem como realizar a Compensação de ausência dos educandos, quando necessário.

No Listão de avaliação, o professor, além de visualizar as atividades avaliativas, digita os conceitos ou notas de seu componente curricular ao final de cada bimestre. As informações das notas/conceitos migram, automaticamente, para o campo de Fechamento.

O Listão de planos de aula apresenta os planejamentos diários em lista, facilitando a visualização dos planos na sequência. O educador também pode realizar seus registros neste campo.

e) Fechamento:

Tela que dispõe da consolidação dos dados pedagógicos bimestrais; apresenta o nome de cada aluno da turma, sua nota/conceito, nota pós-conselho, quantidade de faltas, compensações, frequência (em percentual), conselho de classe (com registros do conselho, como: desenvolvimento e aprendizagem, recomendações ao aluno, recomendações aos pais, parecer conclusivo e visualização dos dados conceituais e de frequência de todos os componentes curriculares da turma) e boletim (que pode ser visto na forma da impressão).

\section{Relatórios}

Para facilitar a análise dos dados inseridos pelos docentes no sistema, o SGP gera relatórios que sintetizam e/ou permitem a análise do desenvolvimento individual dos alunos ou do desenvolvimento da turma no processo de aprendizagem. Estes relatórios possibilitam que professores e gestores analisem o percurso avaliativo e possam fazer os encaminhamentos pertinentes.

Há, no SGP, relatórios para os docentes e relatórios para os gestores. Na aba Relatórios para os docentes, de acordo com as informações inseridas pelo próprio professor, o sistema 
consolida: gráficos das atividades avaliativas (com a tabulação dos resultados de cada atividade avaliativa), tarjeta bimestral (contendo a síntese das notas, faltas, compensação de ausência e porcentagem de frequência no componente curricular), relatório de frequência (indicando a frequência dos estudantes, dia a dia do bimestre), resumo do conteúdo programático e das atividades desenvolvidas (com a descrição das datas e conteúdo de cada aula do bimestre pesquisado), anotações dos alunos (apontamento das anotações registradas sobre os educandos).

$\mathrm{Na}$ aba Relatórios para gestores, com acesso e visualização apenas da equipe gestora da escola, contemplam-se dados mais gerais que auxiliam para uma análise global do processo de aprendizagem. Permitem a consulta de:

a) Ata final de resultados:

É o documento que consolida as notas, frequência, compensação de ausências, porcentagem de frequência, parecer conclusivo e dias letivos de toda a turma. Nesta ata, há a indicação, com diferenciação de cores, dos alunos inativos (transferidos ou desistentes) e alunos com frequência abaixo da porcentagem indicada por lei (Portaria Municipal de São Paulo $\mathrm{n}^{\circ}$ 5.941 de 15 de outubro de 2013).

b) Acompanhamento individual de notas/conceitos:

Esta funcionalidade gera um gráfico que aponta as notas/conceitos bimestrais de cada componente curricular do aluno da turma. É possível, assim, realizar uma observação mais minuciosa do desenvolvimento pedagógico dos estudantes.

c) Síntese da avaliação todos os componentes (barra):

Através desta funcionalidade, o gestor pode visualizar, ao término do bimestre (ou logo após a inserção das notas/conceitos bimestrais realizadas pelos professores) os resultados das atividades avaliativas de cada componente curricular. Há, no gráfico de barras, o detalhamento do quantitativo das notas/conceitos dos alunos por componente.

d) Análise das turmas do ano por componente:

O sistema permite que seja feita a análise comparativa, através de gráfico de barras, do quantitativo das notas/conceitos do mesmo componente curricular em diferentes turmas da mesma série/ciclo.

e) Relatório pedagógico:

Funcionalidade que gera o percurso pedagógico do educando, desde 2014, com a descrição de seu boletim escolar (com notas/conceitos e faltas bimestrais e final do ano letivo; observações do Conselho de classe), observações individuais (migradas da funcionalidade 
Anotações do campo Diário de classe do docente), entre outras informações (como justificativa de faltas e remanejamentos e reclassificações).

\section{Avaliação escolar na perspectiva da aprendizagem}

A discussão sobre a temática da avaliação escolar não é inovadora, tampouco inédita. É um tema perpassado por indagações, reflexões e concepções há tempos. Tantos estudos resultaram na conscientização da relevância da avaliação nas práticas pedagógicas. Afinal, é através da avaliação que é possível analisar e contribuir para o alcance de objetivos do processo de ensino e aprendizagem.

Apesar desta valorização da avaliação no cotidiano escolar, avaliar, por vezes, soa, de maneira preponderante, como um instrumento medidor, com uma finalidade taxativa, até mesmo de característica binômia: aqueles que alcançaram os objetivos e aqueles que não alcançaram. Sob esta perspectiva, a avaliação serviria para classificar e nada mais. Tornar-seia uma comprovação de que o trabalho docente foi realizado, julgado e apresentado em forma de notas ou conceitos. A partir deste cenário, não haveria o que ser feito, em um determinismo, minimante, desumano com os alunos, professores e a educação. A avaliação tomaria um posto soberano na escola de vereditos indiscutíveis mediante a racionalidade dos dados. Pouco importaria, desta forma, o percurso, o (re)planejamento, a individualidade, o ensinar e o aprender dentro de todo o contexto escolar.

O repensar pedagógico, a partir da avaliação, envolve todos os atores da escola, inclusive o aluno, que não é um ser passivo neste processo, ao contrário, é protagonista de sua aprendizagem e precisa ter claro como é avaliado e o que se espera dele. Quando o ato avaliativo permite devolutivas aos estudantes proporcionando a tomada de consciência de suas dificuldades e potencialidades, segundo Gonçalves (2015), o aluno buscará a construção de estratégias que fomentem suas habilidades prol à superação de suas necessidades. Ser um sujeito ativo em sua aprendizagem é ter a oportunidade de refletir e agir diante de objetivos educacionais explícitos, superando a ideia da avaliação como instrumento de ameaça, punição e exclusão (que enfatiza o autoritarismo docente). Valoriza-se, portanto, uma democratização do ensino que implica no acesso do educando à escola, na permanência e na terminalidade de seus estudos (LUCKESI, 1996).

Avaliar, assim, está a serviço da educação. Ao se avaliar para a aprendizagem de todos os alunos, há, de acordo com Hoffmann (1998) o comprometimento dos professores e da escola em emitir juízos de valores e tomar decisões que atendam às necessidades de cada educando, 
respeitando suas diferenças. A avaliação, sob a perspectiva da aprendizagem, é pensada para os alunos e a partir deles, em um contexto coletivo sem exclusões. Sob esta ótica não há avaliação punitiva, que oprime e segrega. O aluno é o motivo do agir pedagógico consciente para a prática de uma educação inclusiva.

\section{O papel do coordenador pedagógico nas ações pedagógicas avaliativas}

"Pela estreiteza ou amplitude do seu olhar [...], o educador é comprometido com o ato avaliativo" (HOFFMANN, 1998, p. 15). Este olhar, no entanto, não é instintivo, é um olhar que necessita ser afinado, racionalizado e embasado teoricamente para ser útil ao processo educacional. Neste contexto, torna-se fundamental a função de um profissional: o coordenador pedagógico. É ele que, diante do cotidiano escolar, problematiza, orienta, acolhe e esclarece, empreendendo ações que busquem favorecer o processo de ensino e aprendizagem (LIBÂNEO, 2005).

Quando se trata do processo avaliativo, é fundamental que haja uma ação pedagógica problematizadora que estimule os educadores a analisar as situações de avaliação e ao replanejamento educacional em busca da superação das dificuldades encontradas. $\mathrm{O}$ coordenador pedagógico, como formador, deverá, então, direcionar as informações fornecidas pelo processo avaliativo em "iniciativas capazes de ajudar professores a ensinar e estudantes a aprender” (MONTEIRO et al., 2012, p. 94). Nesta perspectiva, este profissional, de acordo com Almeida e Placco (2011), tem vinculado a si um papel transformador por relacioná-lo ao compromisso com a criticidade, auxiliando o professor em sua prática reflexiva.

O papel do coordenador pedagógico, de acordo com Monteiro et al. (2012), deixa de ser o de fiscal das práticas educativas e o de gerente das atividades burocráticas, para legitimar-se como formador e parceiro dos educadores. Portanto, ao assumir seu papel formativo, o coordenador pedagógico possibilita melhores condições para que os docentes construam e realizem suas ações para a qualificação do processo de ensino e de aprendizagem, favorecendo um espaço escolar de democratização de conhecimentos para, "de fato, viabilizar o direito de aprender de todos os alunos" (MONTEIRO et al., 2012, p. 33). 


\section{Os recursos tecnológicos como ferramentas facilitadoras ante às avaliações escolares}

Com os recursos tecnológicos disponíveis, atualmente, não é possível desassociar o trabalho educacional das ferramentas digitais. Tratando-se, pontualmente, da tecnologia como forma de registro, é importante ressaltar que esta não pode ser caracterizada como um fim para as atividades na escola. As constatações realizadas com o auxílio de ferramentas tecnológicas não devem ter maior valor do que o olhar curioso e investigativo de cada educador. Os recursos que a tecnologia oferece, por seu dinamismo, transparência e acessibilidade, necessitam se tornar alvo de reflexão dos educadores para que estes caminhem ao alcance dos objetivos da escola. Afinal, a tecnologia possui "um outro espaço criativo, científico, [...] ao acelerar a organização, conferir os dados e analisá-los” (CARVALHO; BARBIERI, 1997, p. 18).

Segundo Hoffmann (1998), o questionamento faz parte do olhar inquiridor do educador. Desta forma, as planilhas, gráficos e relatórios gerados por recursos tecnológicos sem o olhar indagativo do educador não passariam de ferramentas que enfatizam avaliações medidoras com um viés classificatório e excludente. As ferramentas tecnológicas podem ser utilizadas como subsídio do agir pedagógico (RAMOS; COPPOLA, 2009), pois ao proporcionar a análise dos registros do processo avaliativo, assinala-se, de acordo com Almeida e Placco (2006), oportunidades para reflexão das ações educativas em busca da coerência entre o desejado e a realidade, entre a teoria e a prática. Através das informações detalhadas geradas por recursos digitais com o dinamismo próprio das tecnologias, possibilita-se uma análise minuciosa dos educadores diante ao processo avaliativo.

Este movimento de observações e reflexões, mediado pelo Coordenador Pedagógico (enquanto profissional articulador do trabalho coletivo e formador) permite a tomada de decisões que tenham como objetivo a garantia de aprendizagem para todos os alunos. Afinal, segundo Freire (2001, p. 43), "é pensando criticamente a prática de hoje ou de ontem que se pode melhorar a próxima prática”.

\section{Procedimentos metodológicos}

Para a consolidação deste trabalho acadêmico, foi realizada uma pesquisa de campo em escolas de ensino fundamental da rede municipal de ensino da cidade de São Paulo. Devido a Portaria Municipal n 1.224/14 que "institui o Sistema de Gestão Pedagógica - SGP no âmbito da Rede Municipal de Ensino de São Paulo”, todas as Unidades Educacionais, desde então, realizam seus registros pedagógicos neste sistema digital. 
O trabalho de pesquisa centralizou-se na região sul da cidade de São Paulo, especificamente, com as escolas pertencentes à Diretoria Regional de Educação - Santo Amaro. Utilizou-se uma pesquisa de amostragem estratificada (GIL, p. 92, 2008), a qual caracteriza-se pela seleção da amostra de um subgrupo, ou seja, de um determinado conjunto pertencente à um coletivo maior. Ao se realizar uma amostragem estratificada, há o enfoque em propriedades comuns deste conjunto, desta maneira, foram convidadas três escolas (especificamente, uma Coordenadora Pedagógica de cada Unidade Escolar) para participarem da pesquisa. A escolha destas Unidades foi feita com base na indicação do trabalho de destaque das Coordenadoras Pedagógicas que efetivam suas atividades no SGP e socializaram o cumprimento da Portaria 1.224/14 em encontros formativos na Diretoria Regional de Educação - Santo Amaro. As três Coordenadoras Pedagógicas convidadas para participar desta pesquisa demonstraram publicamente, em encontros formativos realizados na Diretoria Regional de Educação - Santo Amaro, o interesse em conhecer e utilizar as variadas funcionalidades do SGP, relacionando-as às práticas da Coordenação Pedagógica.

A pesquisa com as Coordenadoras Pedagógicas foi feita através de questionário online enviado por correio eletrônico às escolas nas quais trabalham. A escolha pela estratégia de pesquisa através de questionário se deu pelo fato de permitir que as entrevistadas respondessem às questões da pesquisa no momento em que julgassem pertinente.

Os dados coletados por meio do questionário respondido pelas Coordenadoras Pedagógicas foram organizados para que possam oferecer proposições acerca da problemática desta pesquisa. As questões fechadas, depois de tabuladas, eletronicamente, conduziram a indícios do que é típico do grupo auxiliando no processo de interpretação das respostas e discussão dos resultados. As questões abertas, de caráter qualitativo, foram analisadas considerando as etapas de Miles e Huberman (1994 apud GIL, 2008, p. 175).

A importância da conceituação dos procedimentos de análises dos dados não se sobressai à reflexão proporcionada pela sistematização das informações. A descrição e organização dos dados obtidos, sejam eles quantitativos ou qualitativos, precisam promover a interpretação das respostas.

\section{Resultados e discussão}

De acordo com as respostas fornecidas pelas três Coordenadoras Pedagógicas de escolas municipais de ensino fundamental da rede municipal de São Paulo, localizadas na Diretoria Regional de Educação - Santo Amaro, é possível analisar e significar as informações obtidas. 
Todas as coordenadoras entrevistadas afirmaram que utilizam o SGP, pelo menos, de duas a três vezes por semana, sendo que, em período de fechamento bimestral, uma delas aponta que faz uso do sistema diariamente.

De quatro ferramentas de avaliação contidas no SGP, as coordenadoras elencaram duas como as mais utilizadas no trabalho da Coordenação Pedagógica: primeiramente, a ferramenta Síntese da avaliação todos os componentes e, como a segunda mais utilizada, a ferramenta Ata final de resultados.

As duas ferramentas elencadas como as menos prioritárias foram a Análise das turmas do ano por componente e o Acompanhamento individual de notas/conceitos. É importante ressaltar, no entanto, que a classificação feita não implica na inutilização de ferramentas, mas reflete, apenas, as funcionalidades do sistema que são menos exploradas pelas coordenadoras entrevistadas.

A funcionalidade Síntese da avaliação todos os componentes, de acordo com a opinião das entrevistadas, possibilitam a discussão, de maneira conjunta entre professores e coordenadores pedagógicos, dos critérios de notas/conceitos atribuídos e a observação, acompanhamento e avaliação do desenvolvimento do processo de aprendizagem dos estudantes.

A ferramenta Ata final de resultados foi apontada como uma das mais utilizadas pelas coordenadoras pedagógicas respondentes do questionário por permitir a visualização ampla de notas/conceitos e frequência da turma, em todos os componentes curriculares, proporcionando o acompanhamento do processo de aprendizagem dos alunos.

As Coordenadoras Pedagógicas também responderam sobre o que o SGP trouxe de vantagens e desvantagens ao desenvolvimento de sua função, após sua implantação na rede municipal de ensino. As desvantagens citadas foram, primeiramente, a apropriação do uso do SGP no ano de implementação e, depois, a lentidão do sistema nos períodos de fechamento do bimestre devido à sobrecarga de acesso dos educadores.

No entanto, foram apontadas muitas vantagens do SGP ao trabalho do Coordenador Pedagógico: a possibilidade de observar e analisar, de maneira célere e sintetizada, os dados avaliativos através das funcionalidades do sistema (como gráficos); o fácil acesso aos registros pedagógicos de todos os componentes curriculares (desde o planejamento anual aos planos de aula); a otimização ao atendimento às famílias (através, especialmente, de relatórios individuais como o Acompanhamento individual de notas/ conceitos); a viabilidade de repensar e replanejar as ações pedagógicas ao visualizar, de forma abrangente, o desenvolvimento da aprendizagem 
dos estudantes nos relatórios oferecidos no sistema, especialmente, durante os Conselhos de Classe.

Por fim, perguntou-se às coordenadoras quais contribuições o uso do SGP pode oportunizar durante os períodos de fechamento do bimestre, considerando o papel formativo de sua função. As repostas se referiram à discussão dos resultados através dos relatórios (gráficos) gerados pelo sistema; celeridade na tabulação dos resultados das atividades avaliativas, auxiliando no replanejamento das ações pedagógicas; possibilidade de registro sobre o desenvolvimento do processo de aprendizagem dos alunos durante o Conselho de Classe (na tela de Fechamento); possibilidade de troca de experiências entre os docentes (estimuladas e intermediadas pela Coordenadora Pedagógica) ao analisar as dificuldades e habilidades das turmas explicitadas nos gráficos gerados a partir das funcionalidades do sistema.

É possível notar que está claro para as Coordenadoras Pedagógicas entrevistadas que os instrumentos avaliativos e sua análise servem para a tomada de consciência da própria prática docente e que são pontos de partida de incentivo do coordenador para que os professores revisitem, constantemente, seus planejamentos de ensino prol da aprendizagem de todos os alunos.

\section{Considerações finais}

As ações pedagógicas em uma escola devem voltar-se, exclusivamente, para a aprendizagem de todos os alunos. Não há sentido o desenvolvimento de atividades com discussões coletivas, amparadas por recursos tecnológicos, articuladas pelo Coordenador Pedagógico, se servirem apenas para alguns; se deixarem, no meio do caminho, aquele rotulado com dificuldade; se predominar a exclusão e a avaliação, portanto, como um fim. As ações avaliativas e os instrumentos utilizados para a análise destes dados só serão válidos se forem caracterizados como apontamento do desenvolvimento dos estudantes para o alcance dos objetivos educacionais.

O Sistema de Gestão Pedagógica (SGP), como ferramenta tecnológica, torna-se um instrumento facilitador para o trabalho de qualificação do processo de ensino e aprendizagem ao permitir que o Coordenador Pedagógico o utilize coletivamente com seus professores. Ao organizar os registros pedagógicos, o SGP possibilita que os Coordenadores Pedagógicos, através das informações geradas pelo sistema e de acesso e apreciação por toda a equipe escolar, promovam a reflexão do direcionamento das ações educacionais. Ao tratar-se da avaliação, em específico, o SGP é apontado pelas Coordenadoras Pedagógicas, entrevistadas nesta pesquisa, 
como instrumento que proporciona questionamentos dos dados sistematizados. Desta maneira, o Coordenador Pedagógico, como articulador e formador, problematiza e orienta as ações que favoreçam o alcance das metas propostas pela escola, levando à reflexão da necessidade de replanejamento em busca da superação das dificuldades encontradas. Afinal, a avaliação deve ser utilizada para pensar e planejar a prática didática (SACRISTÁN; GÓMEZ, 1998).

A avaliação torna-se, assim, com o auxílio dos dados fornecidos e sistematizados pelo SGP, o ponto de partida para a democratização do conhecimento. A constatação de dados, através do SGP, precisa aguçar o olhar investigativo de cada educador, incentivados pelo formador em potencial da escola: o Coordenador Pedagógico. Será através do dinamismo e da facilidade de acesso propiciado pelo SGP, aliados ao papel transformador do Coordenador Pedagógico, que os resultados das ações avaliativas permitirão a análise pelos educadores e posteriores tomadas de decisão do coletivo que visarão garantir a aprendizagem para todos os educandos por meio de uma educação inclusiva.

\section{REFERÊNCIAS}

ALMEIDA, L. R.; PLACCO, V. M. N. de S. (orgs). O papel do coordenador pedagógico. Revista Educação, set. 2011.

CARVALHO, C. P.; BARBIERI, M. R. Formação de professores em tempo de informática. In: UNIVERSIDADE DE SÃO PAULO (USP). Comunicação e Educação. São Paulo: Ed. Moderna, ano III, n. 9, 1997.

FREIRE, P. Pedagogia do oprimido. 20 ed. Rio de Janeiro: Paz e Terra, 2001.

GIL, A. C. Métodos e técnicas de pesquisa social. 6 ed. São Paulo: Atlas, 2008.

GONÇALVES, F. C. N. A. Avaliação escolar: uma estratégia para promoção do protagonismo do aluno. IV Colóquio Internacional: educação, cidadania e exclusão: didática e avaliação. Rio de Janeiro, 2015.

HOFFMANN, J. M. L. Contos e contrapontos: do pensar ao agir em avaliação. Porto Alegre: Mediação, 1998.

LIBÂNEO, J. C. Educação escolar, políticas, estruturas e organização. 2 ed. São Paulo: Cortez, 2005.

LUCKESI, C. C. Avaliação da aprendizagem escolar. $3^{\text {a }}$ ed. São Paulo: Cortez, 1996.

MONTEIRO, E. et al. Coordenador pedagógico: função, rotina e prática. 1 ed. Palmeiras, BA: Instituto Chapada de Educação e Pesquisa, 2012. 
RAMOS, M.; COPPOLA, N. C. O uso do computador e da internet como ferramentas pedagógicas. Paraná, 2009. Disponível em:

www.diaadiaeducacao.pr.gov.br/portals/pde/arquivos/2551-8.pdf. Acesso em: 20 de mar 2018.

SACRISTÁN, J. G; GÓMEZ, A. I. P. Compreender e transformar o ensino. 4 ed. Porto Alegre: ArtMed, 1998.

SÃO PAUlO (SP). Programa Mais Educação São Paulo: subsídios 2: Sistema de Gestão Pedagógica - SGP e a Avaliação para a Aprendizagem/Secretaria Municipal de Educação. São Paulo: SME/ DOT, 2014.

SÃO PAULO (SP). Roteiro de uso. S/d. Disponível em: https://github.com/prefeiturasp/SME-SGP/wiki/Roteiro-de-uso. Acesso em: 20 de mar de 2018.

\section{Como referenciar este artigo}

SILVA, Claudia Gonçalves da; SANTOS, Ricardo dos. Sistema de Gestão Pedagógica (SGP) e avaliação escolar: a influência de uma tecnologia no agir do coordenador pedagógico. Revista on line de Política e Gestão Educacional, Araraquara, v. 24, n. 1, p. 86-99, jan./abr. 2020. eISSN:1519-9029. DOI: https://doi.org/10.22633/rpge.v24i1.12848

Submetido em: 23/06/2019

Revisões requeridas: 05/10/2019

Aprovado em: 23/11/2019

Publicado em: 06/01/2020 